\title{
Understanding the application of stem cell therapy in cardiovascular diseases
}

This article was published in the following Dove Press journal:

Stem Cells and Cloning:Advances and Applications

29 October 2012

Number of times this article has been viewed

\section{Rakesh K Sharma \\ Donald J Voelker \\ Roma Sharma \\ Hanumanth K Reddy}

University of Arkansas for Medical Sciences, Medical Center of South Arkansas, El Dorado, AR, USA
Correspondence: Rakesh K Sharma University of Arkansas for Medical Sciences, Medical Center of South Arkansas, 700 West Grove St, El Dorado, AR-7I730, USA

Tel +l 8708755540

Fax +l 8708755548

Email rsharma@uams.edu
Abstract: Throughout their lifetime, an individual may sustain many injuries and recover spontaneously over a period of time, without even realizing the injury in the first place. Wound healing occurs due to a proliferation of stem cells capable of restoring the injured tissue. The ability of adult stem cells to repair tissue is dependent upon the intrinsic ability of tissues to proliferate. The amazing capacity of embryonic stem cells to give rise to virtually any type of tissue has intensified the search for similar cell lineage in adults to treat various diseases including cardiovascular diseases. The ability to convert adult stem cells into pluripotent cells that resemble embryonic cells, and to transplant those in the desired organ for regenerative therapy is very attractive, and may offer the possibility of treating harmful disease-causing mutations. The race is on to find the best cells for treatment of cardiovascular disease. There is a need for the ideal stem cell, delivery strategies, myocardial retention, and time of administration in the ideal patient population. There are multiple modes of stem cell delivery to the heart with different cell retention rates that vary depending upon method and site of injection, such as intra coronary, intramyocardial or via coronary sinus. While there are crucial issues such as retention of stem cells, microvascular plugging, biodistribution, homing to myocardium, and various proapoptotic factors in the ischemic myocardium, the regenerative potential of stem cells offers an enormous impact on clinical applications in the management of cardiovascular diseases.

Keywords: stem cell therapy, stem cell delivery, cardiovascular diseases, myocardial infarction, cardiomyopathy

\section{Introduction}

Each year, the American Heart Association updates its statistics on heart disease, stroke, and other vascular diseases. Mortality data related to cardiovascular diseases in 2008 accounted for $32.8 \%$ mortality, or one of every three deaths in the United States, suggesting a very high burden of cardiovascular morbidity and mortality. ${ }^{1}$ This emphasizes the need for new cardiovascular interventions that will have some impact on cardiovascular morbidity and mortality.

Utilization of stem cell therapy, through the application of multiple new devices and methods, may offer rapid regeneration of effective myocardium, and thus impact cardiovascular morbidity and mortality. This provides a key to long-term survival in patients with permanent myocardial damage, either by stimulating local generation, or by providing a continuous supply of cardiac stem cells. The study of stem cells and their role in treating cardiovascular diseases is evolving at a rapid pace.

Regeneration and healing of damaged tissue by repair is critical to survival. Repair refers to the restoration of tissue architecture and its function after injury. This process occurs by means of two key steps: regeneration and healing. Some myocardial tissues 
can replace all the damaged tissue, with return of myocardium to more of a normal state; this is the repair process of regeneration. Other tissues may be incapable of restoring the tissue, and repair may partly or completely occur by the laying down of connective tissue or fibrous tissue, thereby leading to healing by scar formation or fibrosis (which involves extensive deposition of collagen as a result of chronic inflammation or necrosis). This repair process involves the proliferation of various cells and close interaction between cells, extra cellular matrix, and cellular paracrine function. The aim of this review is to explore the concept of stem cell therapy for cardiovascular diseases, and to study the science supporting stem cell therapy and methods of delivery of this therapy to patients.

\section{Stem cells and regeneration}

Based on intrinsic abilities of the human body, tissues can be classified in one of three categories: continuously dividing tissues, stable tissues, or permanent tissues. Continuously dividing tissues, such as hematopoietic cells in bone marrow, can readily regenerate. In the category of continuously dividing cells, the mature cells are short-lived and, as such, are continuously replenished by stem cells, creating a constant equilibrium between replication and dying mature cells. This phenomenon is evident in the multilayered epithelium of skin and in the gastrointestinal tract, which is a great example of a stem-cell niche of constantly replenishing dying cells. Stable tissue has cells that are in quiescence, with minimal replicative ability. Typical examples of such tissues include liver and kidney tissue, endothelial cells, fibroblasts, and smooth muscle cells; with the exception of the liver, all of these tissues have only limited capacity to regenerate after injury. Permanent tissue includes the tissues with terminally differentiated cells in postnatal life. Neurons and cardiac muscle cells were thought to belong to this category.

In the past, the accepted notion was that the human heart was a postmitotic organ without any regenerative ability. It was assumed that, in the period after birth to early adulthood, the heart had a relatively stable and slowly decreasing number of myocytes and that myocyte regeneration had little function. ${ }^{2}$ This view is now challenged, and evolving knowledge indicates that these tissues may be stable rather than terminally differentiated.

\section{Evolution of stem cell therapy in cardiovascular diseases}

Approximately 50 years ago, researchers discovered that bone marrow has at least two kinds of stem cells: hematopoietic stem cells, which give rise to blood cells such as red blood cells, neutrophils, basophils, eosinophils, monocytes, macrophages, $\mathrm{B}$ and $\mathrm{T}$ lymphocytes; and bone marrow stromal stem cells, which give rise to bone, cartilage, fat, and cells, called mesenchymal stem cells, that are needed to support the formation of blood and connective tissues. Early experience with intracoronary stem cell therapy for ischemic heart disease was reported by Strauer et $\mathrm{al}^{3}$ from Germany. In this study, researchers tested use of autologous intracoronary mononuclear bone marrow cells 5-9 days after percutaneous transluminal coronary angioplasty (PTCA; performed within 12 hours of myocardial infarction) in ten patients who received stem cell therapy after the PTCA. The patients showed improvement in segmental wall motion at three months. ${ }^{3}$ These results were confirmed in another study, by Assmus et al, ${ }^{4}$ of 20 patients who received intracoronary stem cell therapy 4 days after emergency PTCA for acute myocardial infarction. In this study, bone marrow mononuclear cells (BMC) were used in nine patients, and blood progenitor cells in eleven patients. Injection was performed in the culprit vessel, with reevaluation at 4 months. By as early as 2004 , more than 150 patients had undergone stem cell therapy to attempt myocardial regeneration. ${ }^{5}$

In the United States, the FDA approved the first trial, by Perin et al, ${ }^{6}$ to evaluate BMC. This trial was designed to test BMC use in heart failure patients for hibernating myocardium by improving angiogenesis. This trial showed a $75 \%$ decrease in perfusion defects and an improved ejection fraction ranging from $20 \%$ to $29 \%$. This pilot trial also demonstrated the efficacy of successful direct endocardial injection of autologous BMC. The feasibility and efficacy of intracoronary injection of peripheral blood stem cells, mobilized after granulocyte-colony stimulating factor therapy, was evaluated in the MAGIC stem cell randomized clinical trial. ${ }^{7}$ It showed improvement in cardiac function, and demonstrated promotion of angiogenesis in patients with myocardial infarction.

\section{Stem cell therapeutics}

By definition, the stem cells have to be self-renewing, clonigenic, and multipotent in vitro and in vivo. Stem cells must be able to divide asymmetrically into one daughter cell resembling the mother cell, and the other daughter cell that gives rise to multiple progenies. The result of this asymmetric replication of stem cells is that after each division of stem cells, some progeny enter into the differentiation phase while others remain undifferentiated stem cells, maintaining their self-renewal capacity. ${ }^{8}$ 
A number of experiments have shown that certain stem cells can differentiate into other than the predicted lineage (such as blood stem cell to cardiomyocytes), a process called transdifferentiation. ${ }^{9}{ }^{10}$ Such stem cell differentiation into a specific stem cell type offers the possibility of a renewable source for the replacement of dead or nonfunctional tissues. It is now recognized that stem cells with the capability to generate multiple lineages are present in bone marrow and in other tissues. These are referred to as adult stem cells. Whether these stem cells have the same differentiation plasticity, or differentiation capacity, as embryonic stem cells is the subject of ongoing research. ${ }^{11}$

One of the most exciting aspects of stem cell therapy is therapeutic cloning. ${ }^{12}$ This strategy involves using stem cell culture to produce large numbers of stem cells and then transplanting them into the target organ. In 2006, researchers had a breakthrough whereby they were able to reprogram adult cells to assume a stem cell-like state, called induced pluripotent stem (iPS) cells. ${ }^{13}$

\section{Basic science and potential mechanisms}

Recent identification of different types of progenitor cells in the heart ${ }^{2}, 14$ has suggested that the myocardium is not a terminally differentiated organ as previously believed. The remarkable potential of stem cells to develop into different cells within the human body during life, may serve as an internal repair system to replenish dead or dying cells. Such stem cells can be mobilized from bone marrow, fat, or blood, and then cultured to produce large numbers of cells for transplant into the area of injury.

Evidence challenging traditional wisdom that the heart is a postmitotic organ comes from the concept of cardiac chimerism. In this, female heart transplantation into a male host is followed by the display of significant y-positive myocytes in the female heart, suggesting that male stem cells in circulation went into the female heart and differentiated into three main local cardiac cells..$^{15}$ This observation in the heart transplant patients, that putative stem cells and progenitor cells from recipients were found in the transplanted heart, supports the idea of ongoing regeneration, mediated by circulating stem cells.

Messina et $a{ }^{16}$ have shown that myocardial cells from biopsies were found to have cells with the features of stem cells. These cells exhibited typical features of human circulating endothelial progenitor cells, such as CD34, CD31, KDR and c-kit positive. These markers suggested their origin was from bone marrow, and that subsequently accumulation was in the myocardium. The ability of these endothelial progenitor cells to generate functional myocardium is consistent with their role in cardiac repair. ${ }^{9}$ Furthermore, bone marrow-derived endothelial progenitor cells could reverse the aging-associated decline in cardiac angiogenic activity shown in mice. ${ }^{17}$

Subsequently, local injection of stem cells into myocardium, for myocardial regeneration, was shown in the experimental animal model in a study by Bearzi et al. ${ }^{18}$ The authors showed that injection of human cardiac stem cells directly into the myocardium of immune-suppressed mice led to the generation of a chimeric heart, which contained human myocardium with myocytes, coronary arterioles, and capillaries. This study resolved the question that human cardiac stem cells may be one of the therapies for cardiomyopathy.

The mechanism of myocardial regeneration is unclear in the setting of little or no blood supply. Collateral vessels and oxygen diffusion from the endocardium may provide enough oxygen to preserve progenitor cells, thus allowing for repair; alternately, there may be cell migration from healthy adjacent myocardium, or directly from the circulation. These progenitor cells can differentiate into myocytes and coronary vessels. Several potential mechanisms are possible. Bone marrow mononuclear cells, mesenchymal stem cells, endothelial cells, and hematopoietic cells may have multifactorial mechanisms such as local neovascularization, neoangiogenesis, or involving their paracrine function. Furthermore, the paracrine function of stem cells ${ }^{19}$ may have the positive effect on endogenous cells of promoting angiogenesis and metabolism, or inhibiting apoptosis.

\section{Sources of stem cells}

As there is a rising interest in stem cell therapy, and reference is often made to the embryonic stem cell, one needs to be familiar with the terminology and the different types of stem cells, such as: embryonic stem cells, adult stem cells, cardiac stem cells, mesenchymal stem cells, and induced pluripotent stem cells. It is crucial to be knowledgeable about the multiple sources of stem cells and terminology used in the literature.

\section{Embryonic stem cells}

We are all formed from and made of stem cells. This begins with fertilization. The embryo has an inner layer called the endoderm. Endoderm cells have the potential to produce all kinds of cells. Mammalian development from embryonic stem cells is an irreversible process, in which cells become progressively specialized by a process of differentiation. ${ }^{8}$ 
These embryonic stem cells have only a brief window of opportunity when all of the cells have a capacity to differentiate into any of 220 specialized cells. ${ }^{20}$ In the late state of the embryo, stem cells are already specialized to give rise to only a specific family of cells, such as muscle or bone, and these cells are called multipotent cells. In adults, there may be very few precursors of these embryonic stem cells that may help replenish cells in a particular organ, and these are called adult stem cells. These include bone marrow stem cells, blood stem cells, and fat stem cells.

\section{iPS cells}

iPS cells are cells that have been engineered to change their identity, with reversion to the embryo-like state, without the benefit of eggs or embryos. Like embryonic cells, iPS cells are pluripotent and have the ability to give rise to any type of tissue in an organism, body, or human body. These iPS cells are not extracted from the embryo but, rather, are created from regular adult cells by a "cocktail" of inducers or transcription factors, and are therefore called "induced" pluripotent stem cells. Takahashi and Yamanaka ${ }^{13}$ conceived the idea of introducing a combination of genes into an adult cell in order to reprogram the cell to behave like an embryonic stem cell, hence called a pluripotent stem cell. The challenge then, was to find the two dozen genes that are normally active in embryonic stem cells and introduce that cocktail into the adult cell, to create an iPS cell. Subsequently, Yamanaka found that there was only a need of four genes, delivered by viruses such as Oct4, Sox2, c-Myc, Klf4, to accomplish this. ${ }^{21}$

The development of iPS cells is very exciting, as it avoids the controversial issues of human embryo research. The ability to harvest adult stem cells from an individual and transform them into iPS cells, and then transplant those stem cells into the desired organ, makes for a regenerative therapy of that tissue that is very attractive.

Thus, iPS cells will be genetically and immunologically matched with the recipient body. However, this raises many questions about whether it is really possible to turn back the biological clock of adult cells to an embryonic state. If this is true, this may provide a "fountain of youth," and may help millions of patients escape, or markedly delay, the consequences of disease and aging. The use of cellular engineering to create iPS cells may be the only way to "trick" cells into behaving like embryonic cells, and to turn back the developmental clock of adult cells. The elaborate manipulation required for this process is called cellular programming.
When cellular reprogramming is done by means of nuclear transfer, the process is called cloning. ${ }^{12}$ Cloning involves injection of genetic material from a cell to an egg cell whose DNA has been previously removed. The injected DNA in the egg causes it to develop as an embryo, from which pluripotent stem cells can be extracted. The egg rejuvenates the genetic material of adult donor cells, with restoration of telomere length, which normally wears off with age (the caps protecting the ends of chromosomes). However, the process of cloning does involve embryos, once again raising ethical issues.

iPS cells may offer the possibility of treating harmful mutations that cause diseases. In 2007, researchers showed that iPS cells brought about correction of sickle cell hemoglobin in the animal model, ${ }^{22}$ thereby opening the possibility of genetic treatment of known single mutations. Moreover, the idea of making iPS cells from patients, and then converting these into cell types involved in disease process, may unravel the mystery of treatment in heretofore untreatable conditions, and truly advance the field of new drug development for various diseases. ${ }^{23}$ Future research may focus on conversion of adult cells into iPS cells, and conversion of these iPSC to relevant cell types to treat individual diseases.

\section{Cardiac stem cells}

The human heart has cardiac stem cells that promote regeneration after myocardial infarction. Urbanek et al ${ }^{14}$ showed a 90 -fold increase in cardiac stem cells in acute infarcts and a 26 fold increase in chronic infarcts, suggesting greater activation of cardiac stem cells in acute than in chronic infarct. The author further substantiated this with evidence of a large number of developing myocytes (10,000/gram), smooth muscle cells (1100/gram), and embryonic cells (3500/gram) in the border of the acute zone of infarction. Cell regeneration decreased by $70 \%$ in chronic infarcts, causing predisposition to chronic congestive heart failure. In chronic infarcts, there was telomere attrition, leading to decreased telomerase levels. In this study, they also showed higher telomerase activity: an 8.6 fold rise in acute infarcts, as compared with a 2.6-fold rise in chronic infarcts. Telomerase activity is a marker of growth potential of cardiac stem cells, such as myocytes, endothelial cells, and smooth muscle cell lineages. This activity was very high in the border of acute myocardial infarction. Telomerase protects the DNA at the end of a chromosome during mitosis. As such, this finding has clinical implications for autologous transplantation in end stage cardiomyopathy, with the hope of increasing telomerase activity. 


\section{Mesenchymal stem cells}

Mesenchymal stem cells are nonhematopoietic cells that exist in most of the adult tissues, notably in bone marrow and adipose tissues. ${ }^{24,25}$ These cells have the ability to differentiate, and can be modified in vitro to adopt phenotypic characters of cardiomyocytes and vascular cells. These cells have demonstrated the capacity of myocardial repair in models of cardiac injury. The mechanism of mesenchymal stem cell therapy appears to be predominantly mediated by paracrine function, rather than engraftment in the host myocardium. ${ }^{26}$ These cells have potential allogeneic therapeutic use. ${ }^{27}$

\section{Allogeneic stem cells}

Use of an "off-the-shelf" product made from human mesenchymal cells from a single healthy donor has been proven safe in a Phase I trial. ${ }^{27}$ These mesenchymal cells are precultured from the bone marrow of a healthy donor, enriched with therapeutic properties, and are expected to target the myocardial site of injury due to stromal cell-derived factor-1 (SDF-1). ${ }^{28}$ These mesenchymal stem cells lack major histocompatibility antigen class 2 molecules and the phenotypes of these allogeneic cells in this study were CD145+, CD166+, and CD45-. Use of such allogeneic cells have several potentials, including "off-the-shelf" intravenous use, and are supported by efficacy data in rodents and safety data in humans. ${ }^{27}$ These cells can differentiate into bone, tendon, fat, and muscle. These cells also secrete immunosuppressive cytokines. Moreover, these cells can be administered by minimal invasive approaches, such as the intravenous route. This stem cell type can target and differentiate into cardiac myocytes and blood vessels. ${ }^{29}$

\section{Ideal stem cell to treat cardiovascular diseases}

The race is on to find the best cells for treatment of cardiovascular disease. There is a need to identify the ideal stem cell, ideal receptive environments, and optimal delivery strategies. There is also a need to define the ideal patient population, and ideal time of administration for stem cell therapy. The ideal receptive environment for cell therapy needs to include an environment which supports optimal cell proliferation. The ideal stem cell will be autologous, capable of differentiating into adult cardiac stem cells, and highly resistant to malignant transformation. These may include human mesenchymal cells, ${ }^{27}$ native cardiac stem cells, ${ }^{30}$ endothelial progenitor cells, ${ }^{31}$ or iPS cells. ${ }^{21}$ iPS cells closely resemble embryonic stem cells, which will be directed by a cocktail of proteins that support and regulate embryonic cardiovascular differentiation. ${ }^{32}$ Some of the important local factors may be those that inhibit inflammation and promote cell growth; for example, in rat experiments with hind limb paralysis, embryonic stem cell therapy worked only when adenosine derivatives were given in conjunction with cell therapy. ${ }^{33}$ Moreover, the use of heparin versus bivalirudin during intracoronary stem cell therapy is relevant, as heparin may block SDF-1/CXCR4 signaling, interfering with migration and homing of stem cells. ${ }^{34}$ Heparin may also decrease the circulating levels of vascular endothelial growth factor, which is needed for therapeutic angiogenesis. ${ }^{34,35}$

\section{Delivery of stem cell therapy}

There are multiple modes of stem cell delivery to the heart, ${ }^{36}$ with different cell retention rates that vary depending upon method and site of injection, ie, intracoronary, intramyocardial, or via coronary sinus. Equally important is timing of delivery, as an early inflammatory response may create a hostile environment for local stem cell proliferation, thus inhibiting regeneration of new tissues. Also, a prolonged delay in stem cell delivery may allow fibrosis to set in, causing the therapy to be insufficient. The timing issue is like a dual-edged sword: early administration of cells may aid in retention of cells with better homing signals; however, a long delay may bring about scar formation. This logic has led to early delivery of stem cell therapy, in 5-7 days in the TIME ${ }^{37}$ study, and a delayed strategy in the Late-TIME trial, ${ }^{38}$ as it is harder to deliver stem cell therapy to most patients in the early strategy.

\section{Intracoronary stem cell therapy}

The conceptualization of intracoronary administration stems from the assumption of cell transplantation at the infarction site during the transcoronary passage of cells. This could provide a simple and effective treatment method for specific infarct-related territories, with maximal delivery of stem cells to the infarcted and peri-infarcted areas during the first injection, thus allowing intracoronary cells to "home-in" on these areas in a homogeneous fashion. Retention of cells in the target area will be a central issue. Studies have demonstrated extravasation of BMC to the infarcted area after intracoronary administration. ${ }^{39,40}$ This extravasation of stem cells may be affected by various factors, including chemokines and adhesion molecules induced by ischemic cell injury, and SDF-1. SDF-1 and beta-2-integrin appear to be the key factors. ${ }^{41-43}$

The intracoronary technique involves a standard percutaneous transluminal coronary angioplasty (PTCA) procedure, 
with use of an over-the-wire balloon with central lumen placed at a desired position. Coronary infusion of cells is performed four to six times, with 3-minute sequential balloon inflations followed by 3 -minute rest periods, to create a "stop flow" situation for maximal retention. This delivery method allows maximum time for stem cells to come into contact with the microcirculation of the infarct-related artery, to maximize the opportunity for migration and retention of cells into the infarct and peri-infarct tissues for successful transplantation. Baseline and postprocedure LV angiograms should be performed. The patient must be monitored for 24 hours, with cardiac markers checked at 6 and 12 hours. It may also be intuitive to inject into a contralateral artery if there are well-formed collaterals, in the hope there may be better retention in the desired ischemic area. Imaging studies will be required to confirm whether giving contralateral stem cell injections encourages retention of cells in occluded artery territories. The crucial issues are: retention of cells, microvascular plugging, biodistribution, homing to myocardium and various proapoptotic factors in the ischemic myocardium. ${ }^{44}$ Hofmann et $\mathrm{al}^{45}$ showed that $14 \%-39 \%$ with CD34+ cells were retained in infarcted myocardium. This small study suggested that CD34+ may improve retention whereas Blocklet et $\mathrm{al}^{46}$ showed only $5.5 \%$ retention of CD34+.

Several randomized trials have shown that administration of intracoronary autologous BMC in patients with myocardial infarction results in improved ejection fraction. ${ }^{47,48}$ Other trials have shown evidence of improvement of regional wall LV function. ${ }^{49}$ The Repair-AMI trial ${ }^{50}$ showed a decrease in major adverse events. However after these initial positive publications, several studies have failed to demonstrate that bone marrow nuclear cells improve LV function in the setting of acute myocardial infarction. ${ }^{51-56}$ In the previous studies, most of the autologous bone marrow mononuclear cell implantations were performed 5-7 days following ST elevation myocardial infarction. Of interest is that, in a small cohort of patients in the Repair-AMI trial, it was observed that the most favorable effect on LV function was obtained by delivery of stem cells on the fifth day.

It is a possibility that timing of cell delivery after myocardial infarction may have an influence on treatment. This has fostered much discussion over the timing of stem cell implantation after acute myocardial infarction. As we know, within hours of acute myocardial infarction there is a welldocumented increase in circulating progenitor cells released from bone marrow. ${ }^{57-59}$ This includes the release of increasing numbers of hematopoietic stem cells, endothelial progenitor stem cells, mesenchymal stem cells, and a very small number of embryonic-like cells with pluripotent properties. ${ }^{60}$

Some of the concerns in regard to negative findings have been related to inadequate cell count, improper processing, and timing of administration. The National Heart Lung and Blood Institute sponsored the Cardiovascular Cell Therapy Research Network and developed two prospective clinical trials, TIME ${ }^{37}$ and LateTIME. ${ }^{38}$ The TIME trial was designed to compare the effects of bone marrow mononuclear source cells delivered in patients with predominantly ST elevation myocardial infarction at 3 to 7 days. The LateTIME trial was developed to test the hypothesis as to whether delayed delivery of autologous bone marrow cells, at 2 to 3 weeks following acute myocardial infarction, would improve global LV systolic function. Cell count and processing issues were clarified by the LateTIME trial, ${ }^{61}$ which did not show any detectable improvement in LV function over a period of 2 years.

\section{Intramyocardial stem cell therapy}

Intramyocardial injection of stem cells is the most invasive approach and is performed via an endocardial approach or during open heart surgery. During open-heart surgery, the injection process is simple. It is performed under direct visualization, allowing for evaluation of the potential target. With this method, one may not be able to access all the areas of the heart.

Transendocardial injection guided by LV electromechanical mapping with NOGA $^{\mathrm{TM}}$ software (Biologics Delivery Systems, Diamond Bar, CA) can help deliver therapy to the target infarct area. ${ }^{62}$ Using NOGA, cells are directly injected into nonviable myocardium, with an 8Fr MYOSTARTM catheter (Biologics Delivery Systems). This catheter has nitinol tubing that contains a retractable needle for injections. Depending upon the LV wall thickness, the needle length can be set up as 4.5-6 mm. Once endocardial contact is made and the appropriate angle under fluoroscopy is determined, $0.3 \mathrm{cc}$ of stem cells are injected by manually advancing the needle. Additional injections are spaced by $1 \mathrm{~cm}$, and will be guided by NOGA. ${ }^{63}$ However, it is important to refrain from using this transendocardial approach in areas of thinned myocardium (thickness less than $5 \mathrm{~mm}$ by MRI). After the procedure, LV angiography should be performed and the patient should be monitored for 18-24 hours. In the United States, the first FDA-approved trial was designed to test the hypothesis that intramyocardial injection of autologous BMC would benefit patients with heart failure by salvaging hibernating myocardium and by improving angiogenesis. ${ }^{6}$ This trial showed a $75 \%$ decrease in perfusion defects and improved ejection fraction ranging from $20 \%$ to $29 \%$. 


\section{Retrograde coronary sinus injection}

Several approaches have been used to deliver potentially therapeutic stem cells. Retrograde infusion using the coronary sinus is the least studied at this time. This modality typically involves placement of a double lumen catheter with a larger proximal balloon and a smaller distal balloon, with the delivery of therapeutic cells at, and beyond, the distal lumen. The distal balloon is used to prevent washout of cells. The cells are injected once catheter placement is confirmed angiographically in the mid- to distal interventricular vein, which runs parallel to the left anterior descending artery. In one of the swine models, $10^{7}$ cells (in $10 \mathrm{cc}$ ) were injected at a pressure of $150 \pm 16 \mathrm{~mm} \mathrm{Hg}$ for $8 \pm 3$ seconds, and both balloons were deflated at 5 minutes postdelivery, to maximize local delivery. ${ }^{36}$ In this study $43 \% \pm 3 \%$ delivered cell exit to lungs in retrograde coronary sinus injection and $41 \% \pm 1 \%$ exit to lungs with intracoronary injections. Furthermore, retention with the intramyocardial route was the highest, with $26 \% \pm 3 \%$ exit to lungs.

\section{Intravenous}

This is the simplest approach but, depending upon the IV access site, cells may become trapped in the lungs, liver, and spleen, so that only a small number may enter coronary circulation, and myocardial homing will be minimal. ${ }^{62}$ Myocardial homing depends on multiple microenvironmental factors, such as expression of adhesion molecules, cytokines, and homing receptors.

\section{Discussion}

During life, an individual may sustain many injuries and recover spontaneously over a period of time, without even realizing the injury in the first place. Wound healing occurs due to a proliferation of stem cells capable of restoring the injured tissue. These stem cells contain the genetic blueprint or memory of how this particular tissue was constructed to begin with. Similarly, regenerative potential by stem cells offers an enormous impact on clinical applications. These potentials may arise from the multiple functions of stem cells, such as self-renewal, multipotency, and paracrine functions. There may be benefits from the paracrine secretion of growth factors or cytokines by a number of retained cells, leading to further mobilization of endogenous progenitor cells. We do not understand the underlying mechanism of stem cell regeneration and healing, just as, at one time in history, we had no concept of the mechanism of action, and benefits, of aspirin, even though the benefits were there long before we understood the mechanism.
The amazing capacity of embryonic stem cells ${ }^{11}$ to give rise to virtually any type of tissue has intensified the search for a similar cell lineage in adults. However, these adult stem cells have the complex tasks of taking up residence in just the right place in order to gain the necessary shape, and of assuming paracrine functions, and then must perform their multiple functions in a complex variety of different cellular environments. Due to the remarkable plasticity of stem cells, one can imagine the exciting possibility of a universal stem cell that can circulate throughout the body and reside wherever needed to promote regeneration of local tissue. However, the major challenge is retention of these cells after implantation via intracoronary, intramyocardial, and retrograde coronary sinus approach. Since a significant percent of stem cells leave the heart soon after administration, ${ }^{36}$ the clinical ramifications may be significant. These stem cells have multiple functions and can be proangiogenic and proparacrine, thereby elaborating potentially detrimental substances in nontarget organs.

Perhaps the major hurdles to the clinical application of research in regard to adult stem cells are the small number of cells that can be isolated from any adult tissue with successful propagation of multipotent adult stem cells ${ }^{64}$ and the development of perfect "cocktails" for optimizing the proliferation of adult stem cells. ${ }^{65}$ This implies that expansion of adult stem cells in culture may be the answer, although one must keep in mind that extensive cultures of human adult cells may suddenly change their intrinsic properties in vivo, rendering them unfit for restoring injured or diseased tissue in patients.

Obviously, stem cell therapy will have a wide spectrum of clinical applications in cardiovascular medicine. This treatment may even have a role in reversing the aging process, which is a natural phenomenon. With the aging process, there is a decline in stem cell number and viability. Moreover, aging and disease are interlinked. Therefore, stem cells may provide a treasure trove of renewable life, and a "fountain of youth."

\section{Disclosure}

The authors report no conflicts of interest in this work.

\section{References}

1. Roger VL, Go AS, Lloyd-Jones DM, et al. Heart disease and stroke statistics - 2012 update: a report from the American Heart Association. Circulation. 2012;125(1):e2-e220.

2. Beltrami AP, Barlucchi L, Torella D, et al. Adult cardiac stem cells are multipotent and support myocardial regeneration. Cell. 2003;114(6) $763-776$. 
3. Strauer BE, Brehm M, Zeus T, et al. Repair of infarcted myocardium by autologous intracoronary mononuclear bone marrow cell transplantation in humans. Circulation. 2002;106(15):1913-1918.

4. Assmus B, Schächinger V, Teupe C, et al. Transplantation of Progenitor Cells and Regeneration Enhancement in Acute Myocardial Infarction (TOPCARE-AMI). Circulation. 2002;106(24):3009-3017.

5. Chachques JC, Acar C, Herreros J, et al. Cellular cardiomyoplasty: clinical application. Ann Thorac Surg. 2004;77(3):1121-1130.

6. Perin EC, Dohmann HF, Borojevic R, et al. Transendocardial, autologous bone marrow cell transplantation for severe, chronic ischemic heart failure. Circulation. 2003;107(18):2294-2302.

7. Kang HJ, Kim HS, Zhang SY, et al. Effects of intracoronary infusion of peripheral blood stem-cells mobilised with granulocyte-colony stimulating factor on left ventricular systolic function and restenosis after coronary stenting in myocardial infarction: the MAGIC cell randomised clinical trial. Lancet. 2004;363(9411):751-756.

8. Moore KL, Persaud TVN. The Developing Human; Clinically Oriented Embryology. 8th ed. Philadelphia: Saunders; 2007.

9. Badorff C, Brandes RP, Popp R, et al. Transdifferentiation of bloodderived human adult endothelial progenitor cells into functionally active cardiomyocytes. Circulation. 2003;107(7):1024-1032.

10. Wagers AJ, Weissman IL. Plasticity of adult stem cells. Cell. 2004;116(5): 639-648.

11. Rosenthal N. Prometheus's vulture and the stem-cell promise. $N$ Engl J Med. 2003;349(3):267-274.

12. Hochedlinger K, Jaenisch R. Nuclear transplantation, embryonic stem cells, and the potential for cell therapy. N Engl J Med. 2003;349(3): 275-286.

13. Takahashi K, Yamanaka S. Induction of pluripotent stem cells from mouse embryonic and adult fibroblast cultures by defined factors. Cell. 2006;126(4):663-676.

14. Urbanek K, Torella D, Sheikh F, et al. Myocardial regeneration by activation of multipotent cardiac stem cells in ischemic heart failure. Proc Natl Acad Sci U S A. 2005;102(24):8692-8697.

15. Quaini F, Urbanek K, Beltrami AP, et al. Chimerism of the transplanted heart. N Engl J Med. 2002;346(1):5-15.

16. Messina E, De Angelis L, Frati G, et al. Isolation and expansion of adult cardiac stem cells from human and murine heart. Circ Res. 2004; 95(9):911-921.

17. Edelberg JM, Tang L, Hattori K, Lyden D, Rafii S. Young adult bone marrow-derived endothelial precursor cells restore aging-impaired cardiac angiogenic function. Circ Res. 2002;90(10):E89-E93.

18. Bearzi C, Rota M, Hosoda T, et al. Human cardiac stem cells. Proc Natl Acad Sci U S A. 2007;104(35):14068-14073.

19. Ratajczak MZ, Kucia M, Jadczyk T, et al. Pivotal role of paracrine effects in stem cell therapies in regenerative medicine: can we translate stem cell-secreted paracrine factors and microvesicles into better therapeutic strategies? Leukemia. 2012;26(6):1166-1173.

20. Shevde N. Stem cells: Flexible friends. Nature. 2012;483(7387): S22-S26.

21. Yamanaka S. Induction of pluripotent stem cells from mouse fibroblasts by four transcription factors. Cell Prolif. 2008;41 Suppl 1:S51-S56.

22. Hanna J, Wernig M, Markoulaki S, et al. Treatment of sickle cell anemia mouse model with iPS cells generated from autologous skin. Science. 2007;318(5858):1920-1923.

23. Lee H, Park J, Forget BG, Gaines P. Induced pluripotent stem cells in regenerative medicine: an argument for continued research on human embryonic stem cells. Regen Med. 2009;4(5):759-769.

24. Bianco P, Riminucci M, Gronthos S, Robey PG. Bone marrow stromal stem cells: nature, biology, and potential applications. Stem Cells. 2001;19(3):180-192.

25. Zannettino AC, Paton S, Arthur A, et al. Multipotential human adiposederived stromal stem cells exhibit a perivascular phenotype in vitro and in vivo. J Cell Physiol. 2008;214(2):413-421.

26. Psaltis PJ, Zannettino AC, Worthley SG, Gronthos S. Concise review: mesenchymal stromal cells: potential for cardiovascular repair. Stem Cells. 2008;26(9):2201-2210.
27. Hare JM, Traverse JH, Henry TD, et al. A randomized, double-blind, placebo-controlled, dose-escalation study of intravenous adult human mesenchymal stem cells (prochymal) after acute myocardial infarction. J Am Coll Cardiol. 2009;54(24):2277-2286.

28. Zhuang Y, Chen X, Xu M, Zhang LY, Xiang F. Chemokine stromal cell-derived factor 1/CXCL12 increases homing of mesenchymal stem cells to injured myocardium and neovascularization following myocardial infarction. Chin Med J (Engl). 2009;122(2):183-187.

29. Quevedo HC, Hatzistergos KE, Oskouei BN, et al. Allogeneic mesenchymal stem cells restore cardiac function in chronic ischemic cardiomyopathy via trilineage differentiating capacity. Proc Natl Acad Sci U S A. 2009;106(33):14022-14027.

30. Bolli R, Chugh AR, D'Amario D, et al. Cardiac stem cells in patients with ischaemic cardiomyopathy (SCIPIO): initial results of a randomised phase 1 trial. Lancet. 2011;378(9806):1847-1857.

31. Szmitko PE, Fedak PW, Weisel RD, Stewart DJ, Kutryk MJ, Verma S. Endothelial progenitor cells: new hope for a broken heart. Circulation. 2003;107(24):3093-3100

32. Takahashi K, Okita K, Nakagawa M, Yamanaka S. Induction of pluripotent stem cells from fibroblast cultures. Nat Protoc. 2007;2(12): 3081-3089.

33. Deshpande DM, Kim YS, Martinez T, et al. Recovery from paralysis in adult rats using embryonic stem cells. Ann Neurol. 2006;60(1): $32-44$.

34. Seeger FH, Rasper T, Fischer A, et al. Heparin disrupts the CXCR4/ SDF-1 axis and impairs the functional capacity of bone marrow-derived mononuclear cells used for cardiovascular repair. Circ Res. Epub July 19, 2012.

35. Kapur NK, Shenoy C, Yunis AA, et al. Distinct effects of unfractionated heparin versus bivalirudin on circulating angiogenic peptides. PLoS One. 2012;7(4):e34344.

36. Hou D, Youssef EA, Brinton TJ, et al. Radiolabeled cell distribution after intramyocardial, intracoronary, and interstitial retrograde coronary venous delivery: implications for current clinical trials. Circulation. 2005;112(Suppl 9):I150-I156.

37. Traverse JH, Henry TD, Vaughan DE, et al; Cardiovascular Cell Therapy Research Network (CCTRN). Rationale and design for TIME: a phase II, randomized, double-blind, placebo-controlled pilot trial evaluating the safety and effect of timing of administration of bone marrow mononuclear cells after acute myocardial infarction. Am Heart J. 2009;158(3):356-363.

38. Traverse JH, Henry TD, Vaughan DE, et al; Cardiovascular Cell Therapy Research Network. LateTIME: a phase-II, randomized, doubleblinded, placebo-controlled, pilot trial evaluating the safety and effect of administration of bone marrow mononuclear cells 2 to 3 weeks after acute myocardial infarction. Tex Heart Inst J. 2010;37(4):412-420.

39. Saito T, Kuang JQ, Lin CC, Chiu RC. Transcoronary implantation of bone marrow stromal cells ameliorates cardiac function after myocardial infarction. J Thorac Cardiovasc Surg. 2003;126(1):114-123.

40. Aicher A, Brenner W, Zuhayra M, et al. Assessment of the tissue distribution of transplanted human endothelial progenitor cells by radioactive labeling. Circulation. 2003;107(16):2134-2139.

41. Ceradini DJ, Kulkarni AR, Callaghan MJ, et al. Progenitor cell trafficking is regulated by hypoxic gradients through HIF-1 induction of SDF-1. Nat Med. 2004;10(8):858-864

42. De Falco E, Porcelli D, Torella AR, et al. SDF-1 involvement in endothelial phenotype and ischemia-induced recruitment of bone marrow progenitor cells. Blood. 2004;104(12):3472-3482.

43. Chavakis E, Aicher A, Heeschen C, et al. Role of beta2-integrins for homing and neovascularization capacity of endothelial progenitor cells. J Exp Med. 2005;201(1):63-72.

44. Geng YJ. Molecular mechanisms for cardiovascular stem cell apoptosis and growth in the hearts with atherosclerotic coronary disease and ischemic heart failure. Ann N Y Acad Sci. 2003;1010:687-697.

45. Hofmann M, Wollert KC, Meyer GP, et al. Monitoring of bone marrow cell homing into the infarcted human myocardium. Circulation. 2005;111(17):2198-2202. 
46. Blocklet D, Toungouz M, Berkenboom G, et al. Myocardial homing of nonmobilized peripheral-blood CD34+ cells after intracoronary injection. Stem Cells. 2006;24(2):333-336.

47. Schächinger V, Erbs S, Elsässer A, et al. Intracoronary bone marrowderived progenitor cells in acute myocardial infarction. $N$ Engl J Med. 2006;355(12):1210-1221.

48. Wollert KC, Meyer GP, Lotz J, et al. Intracoronary autologous bonemarrow cell transfer after myocardial infarction: the BOOST randomised controlled clinical trial. Lancet. 2004;364(9429):141-148.

49. Janssens S, Dubois C, Bogaert J, et al. Autologous bone marrowderived stem-cell transfer in patients with ST-segment elevation myocardial infarction: double-blind, randomised controlled trial. Lancet. 2006;367(9505):113-121.

50. Schächinger V, Erbs S, Elsässer A, et al; REPAIR-AMI Investigators. Improved clinical outcome after intracoronary administration of bonemarrow-derived progenitor cells in acute myocardial infarction: final 1-year results of the REPAIR-AMI trial. Eur Heart J. 2006;27(23):2775-2783.

51. Lunde K, Solheim S, Aakhus S, et al. Intracoronary injection of mononuclear bone marrow cells in acute myocardial infarction. $N$ Engl J Med. 2006;355(12):1199-1209.

52. Tendera M, Wojakowski W, Ruzyłło W, et al; REGENT Investigators. Intracoronary infusion of bone marrow-derived selected CD34+CXCR4+ cells and non-selected mononuclear cells in patients with acute STEMI and reduced left ventricular ejection fraction: results of randomized, multicentre Myocardial Regeneration by Intracoronary Infusion of Selected Population of Stem Cells in Acute Myocardial Infarction (REGENT) Trial. Eur Heart J. 2009;30(11):1313-1321.

53. Hirsch A, Nijveldt R, van der Vleuten PA, et al; HEBE Investigators. Intracoronary infusion of mononuclear cells from bone marrow or peripheral blood compared with standard therapy in patients after acute myocardial infarction treated by primary percutaneous coronary intervention: results of the randomized controlled HEBE trial. Eur Heart J. 2011;32(14):1736-1747.

54. Roncalli J, Mouquet F, Piot C, et al. Intracoronary autologous mononucleated bone marrow cell infusion for acute myocardial infarction: results of the randomized multicenter BONAMI trial. Eur Heart J. 2011;32(14):1748-1757.
55. Traverse JH, McKenna DH, Harvey K, et al. Results of a phase 1, randomized, double-blind, placebo-controlled trial of bone marrow mononuclear stem cell administration in patients following ST-elevation myocardial infarction. Am Heart J. 2010;160(3):428-434

56. Wöhrle J, Birkemeyer R, Markovic S, et al. Prospective randomised trial evaluating a paclitaxel-coated balloon in patients treated with endothelial progenitor cell capturing stents for de novo coronary artery disease. Heart. 2011;97(16):1338-1342.

57. Shintani S, Murohara T, Ikeda H, et al. Mobilization of endothelial progenitor cells in patients with acute myocardial infarction. Circulation. 2001;103(23):2776-2779.

58. Leone AM, Rutella S, Bonanno G, et al. Mobilization of bone marrowderived stem cells after myocardial infarction and left ventricular function. Eur Heart J. 2005;26(12):1196-1204

59. Massa M, Rosti V, Ferrario M, et al. Increased circulating hematopoietic and endothelial progenitor cells in the early phase of acute myocardial infarction. Blood. 2005;105(1):199-206.

60. Wojakowski W, Landmesser U, Bachowski R, Jadczyk T, Tendera M. Mobilization of stem and progenitor cells in cardiovascular diseases. Leukemia. 2012;26(1):23-33.

61. Traverse JH, Henry TD, Ellis SG, et al; for Cardiovascular Cell Therapy Research Network. Effect of intracoronary delivery of autologous bone marrow mononuclear cells 2 to 3 weeks following acute myocardial infarction on left ventricular function: the LateTIME randomized trial. JAMA. 2011;306(19):2110-2119.

62. Perin EC, Geng YJ, Willerson JT. Adult stem cell therapy in perspective. Circulation. 2003;107(7):935-938.

63. Smits PC, van Geuns RJ, Poldermans D, et al. Catheter-based intramyocardial injection of autologous skeletal myoblasts as a primary treatment of ischemic heart failure: clinical experience with six-month follow-up. J Am Coll Cardiol. 2003;42(12):2063-2069.

64. Jiang Y, Jahagirdar BN, Reinhardt RL, et al. Pluripotency of mesenchymal stem cells derived from adult marrow. Nature. 2002;418(6893): 41-49.

65. Deasy BM, Qu-Peterson Z, Greenberger JS, Huard J. Mechanisms of muscle stem cell expansion with cytokines. Stem Cells. 2002;20(1): $50-60$
Stem Cells and Cloning: Advances and Applications

\section{Publish your work in this journal}

Stem Cells and Cloning: Advances and Applications is an international, peer-reviewed, open access journal. Areas of interest in stem cell research include: Embryonic stem cells; Adult stem cells; Blastocysts; Cordblood stem cells; Stem cell transformation and culture; Therapeutic cloning; Umbilical cord blood and bone marrow cells; Laboratory,

\section{Dovepress}

animal and human therapeutic studies; Philosophical and ethical issues related to stem cell research. This journal is indexed on CAS. The manuscript management system is completely online and includes a quick and fair peer-review system. Visit http://www.dovepress.com/ testimonials.php to read real quotes from published authors. 